\title{
1 Acoustic detection of larval fish aggregations in Galician waters (NW Spain)
}

3 Running page head: Acoustic detection of fish larvae

4

5 Eva García-Seoane*, Gustavo Álvarez-Colombo, Joan Miquel, José María Rodríguez, Carlos Guevara-

6 Fletcher, Paula Álvarez, and Fran Saborido-Rey

7

8 E. García-Seoane ${ }^{1}$, and F. Saborido-Rey. Instituto de Investigaciones Marinas (CSIC). C/Eduardo Cabello, 96.36208 Vigo, Pontevedra, Spain (e-mail: evagseoane@gmail.com and fran@iim.csic.es)

10 G. Álvarez-Colombo. Instituto Nacional de Investigación y Desarrollo Pesquero (INIDEP). CC 175, (7600) Mar 11 del Plata, Argentina (e-mail: acolombo@inidep.edu.ar).

J. Miquel. Instituto Español de Oceanografía, Centre Oceanogràphic de les Balears (IEO). Moll de Ponent, s/n, P.O. Box 291. 07080 Palma de Mallorca, Spain (e-mail: joan.miquel@ba.ieo.es ).

J. M. Rodríguez. Instituto Español de Oceanografía, Centro Oceanográfico de Gijón (IEO). Avda. Príncipe de Asturias 70Bis. 33213, Gijón, Asturias, Spain (e-mail:j.m.rodriguez@gi.ieo.es ).

Carlos Guevara-Fletcher, and Paula Álvarez. AZTI-Tecnalia, Marine Research Division, C/ Herrera Kaia, Portualdeaz.g. 20110 Pasaia, Gipuzkoa, Spain (e-mail: cfletcher@azti.esandpalvarez@azti.es ).

Corresponding author: E. García-Seoane: +34986231930; fax: +34986292762; e-mail: evagseoane@gmail.com

\footnotetext{
${ }^{1}$ Present address: Instituto Português do Mar e Atmosfera (IPMA)- Av. Brasília, s/n, 1449-006 Lisboa, Portugal.
} 


\section{Abstract}

An acoustic study was conducted in the Galician shelf (NW Spain) during the late winter of 2012, to detect and assess larval fish abundance. An echo sounder operating with 18, 38, 70, 120 and $200 \mathrm{kHz}$ split-beam, hull-mounted transducers was employed. We analyzed the acoustic records in order to describe vertical and horizontal distribution patterns of larval fish aggregations. Regressions between acoustic backscattered energy and density of the most abundant species (Micromesistius poutassou) indicated that larvae with a swimbladder incremented notably the acoustic response at 38, 70 and $120 \mathrm{KHz}$. However, the predicted acoustic resonance at larval size and depth shows that the $120 \mathrm{kHz}$ is unlikely being effective to detect fish larvae. Contribution of zooplankton (fish larvae excluded) to total scattering was negligible even at the higher frequencies, except for several groups of fluid-like zooplankton, such as chaetognats and polychaets. Horizontal and vertical distribution of acoustic backscattering also indicated that larval fish aggregations can be detected in Galician waters with acoustics, and suggest this technique as a useful tool to overcome difficulties associated with larval ecology and fish recruitment studies.

Keywords: acoustics, fish larvae, frequency response, Galician shelf, zooplankton 


\section{Introduction}

The embryonic and larval periods in fish have important ecological and evolutionary functions. For many species, they represent an effective means of dispersal that can extend the range of a population and mix the gene pool (Cowen \& Sponaugle 2009, Pusack et al. 2014). They are also interactive components of the pelagic ecosystem that can, for example, temporarily reduce local zooplankton populations, so that the potential for competition for food is heightened (Nielsen \& Munk 1998, Beaugrand et al. 2003). However, one of the most important reasons for studying the early life stages of fishes is that the year-class strength of fish populations is determined at these stages, shortly after the yolk-sac depletion, when larvae must find suitable amounts and types of plankton prey (Hjort 1914, Houde 2008). Predicting recruitment represents a challenge in fisheries science, and our ability to do that remains poor. To estimate larval fish abundance is a complex and difficult process involving elaborated and expensive surveys, but such surveys provide detailed descriptions of phenological relationships affecting recruitment (Hare 2014). Additionally, understanding dispersal distance is important for a variety of reasons, including fisheries management, effective marine protected areas design, and control of invasive species (Cowen et al. 2006, Becker et al. 2007, Almany et al. 2009, Cowen \& Sponaugle 2009, Aiken \& Navarrete 2011, Le Corre et al. 2012). Long-time series of egg and larval abundance and distribution data facilitate a spatial comparison of spawning habitats (Van der Lingen \& Huggett 2003, Ibaibarriaga et al. 2007, Álvarez \& Chifflet 2012) and play an important role in fishery management of many species through applying egg and larval production methods to estimate fish stock biomass (Motos et al. 1996, Stratoudakis et al. 2004, Lo et al. 2009).

To sample fish larvae effectively, proper nets and efficient sampling designs are required. These conventional sampling methods, however, suffer from many well-known drawbacks, including those related with sampling devices, larval size and larval behavior, such as net avoidance, extrusion and clogging (Barkley 1972, Wiebe et al. 1982, Leslie \& Timmins 1989, Johnson \& Morse 1994, Hernandez Jr et al. 2011), and problems associated with the nature of sequential sampling. The high 
patchiness and low mean density, typically shown by larval distribution, contribute to increase in variance and uncertainty, and reduces precision of abundance estimations (Lo et al. 2009). Methods that overcome such limitations are required (e.g., acoustic and molecular techniques).The virtues of echo sounder records are the speed of areal coverage and the real-time data presentation of the echogram.

The acoustic method is often used for abundance estimation of juvenile and adult fish of commercially important stocks worldwide (Misund 1997). Also, plankton has been studied acoustically for many years, and the growing importance of this field is now evident (MacLennan \& Holliday 1996). The increased use of acoustics may help elucidate some problems related with the estimation of larval fish abundance (Rudstam et al. 2002, Godø et al. 2014). However, to date, few studies on fish larvae applying the acoustic techniques have been carried out. In order to assess the Engraulis encrasicolus larval distribution in the Strait of Sicily, Bonanno et al. (2006) divided the acoustic signal according to the percentages of zooplankton and fish larvae found in biological samples. Rudstam et al. (2002) concluded that it is difficult to exclude noise or invertebrate targets in the abundance estimates of fish larvae smaller than $15 \mathrm{~mm}$, although they reported reliable estimates of abundance of fish as small as $15 \mathrm{~mm}$.

In the case of fish with small-volume swimbladders, e.g., fish larvae and mesopelagic fish, the likelihood of acoustic detection is increased at low frequencies due to resonance scattering (Godø et al. 2009). Using theoretical models, Miyashita (2003) estimated higher sound scattering levels at 38 $\mathrm{kHz}$ than at $120 \mathrm{kHz}$ for Euonymus japonicus post-larvae with inflated swimbladders during the night. Recently, in the Argentinean shelf, Álvarez-Colombo et al. (2011) detected Merluccius hubbsi aggregations acoustically, in coincidence with the development of larval functional swimbladders at about $4 \mathrm{~mm}$ total length. These authors demonstrated that the high-intensity levels of acoustic backscattering recorded from these aggregations at $38 \mathrm{kHz}$ were due to resonance scattering, 
detection and spatial distribution analysis of larval fish aggregations. This innovative use of acoustics should be contrasted not only in other fish species but also in different geographical areas.

The aim of this study was to test the hypothesis that larval fish aggregations may be detected and assessed by acoustic techniques in the waters of the Iberian Peninsula. We analyzed the acoustic records in order to estimate abundance, and to describe horizontal and vertical distribution patterns of larval fish aggregations. We tested our hypothesis in the Galician shelf (NW of Spain) during the course of a holistic research project on hake recruitment. This region is located in the northern border of the seasonal coastal upwelling that extends along the eastern coasts of the North Atlantic, and whose intensity depends on the North Atlantic anticyclonic eddy (McClain et al. 1986). The upwelling is associated with high primary productivity which determines the structure of the pelagic and benthic food webs (Fariña et al. 1997). This produces one of the most important and intensive fisheries in the European Union, making this area the most fishing-dependent region in Europe (Surís-Regueiro \& Santiago 2014).

\section{Methods}

\section{Biological sampling}

Within the framework of the research project on hake recruitment ecology, a specific cruise (Cramer1203) was carried out off the NW Iberian Peninsula (Fig. 1) in the late winter of 2012 (from February 28 to March 13), during the main spawning peak of this species in the region. The sampling design covered the area from Finisterre to Estaca de Bares, from a depth of around $40 \mathrm{~m}$ to $500 \mathrm{~m}$. Considering that hake presents a highly aggregated spawning behavior, adaptive cluster sampling was implemented starting with a grid of 80 stations arranged in 15 transects perpendicular to the coastline. The distance between stations was $4 \mathrm{~nm}$, and $8 \mathrm{~nm}$ between transects (Fig. 1). Four stations were not included in the study because of sampling errors.

At the sampling grid stations, zooplankton was collected at five fixed-depth strata $(0-20,20-40$, 40-60, 60-100 and 100-200 m depth), with a multiple opening/closing MultiNet MiDi, $50 \times 50 \mathrm{~cm}$ 
aperture (MultiNet Hydro-Bios Apparatebau), equipped with 5 nets of $200 \mu \mathrm{m}$ mesh size. The net, programmed to open/close at the predefined depths, was towed obliquely, from $200 \mathrm{~m}$ depth or from $\sim 10 \mathrm{~m}$ above the bottom, at shallower stations. The tow speed was $2.5-3$ knots, and the retrieval rate of the net was $20 \mathrm{~m}$ per minute. The volume of water filtered in each stratum was measured by an electronic flow meter located in the mouth of the net. Samples were immediately preserved in a $5 \%$ solution of buffered formalin and seawater.

In the laboratory, all fish larvae were sorted from the samples and identified up to the lowest taxonomic level possible. Larvae of the most abundant taxa (those with $\geq 20$ larvae caught, both day and night) were photographed with a Nikon Act-2u camera, and subsequently measured for standard length using the ImageJ $1.45 \mathrm{~s}$ image analysis software (available at http://rsb.info.nih.gov/). Larval lengths were not corrected for shrinkage (Theilacker 1980).

Zooplankton samples (fish larvae excluded) collected with the Multinet Midi were analyzed using a semiautomated zooplankton counting and classification method. For each zooplankton sample, the whole volume was measured and a subsample of $5 \mathrm{ml}$ was taken and stained. The stained samples were digitized using an EPSON V750 PRO scanner (VueScan Professional Edition 8.5.02 software) generating an image resolution of $2400 \mathrm{dpi}$. After that, images were analyzed using Zoolmage free software (licensed under GNU/GPL) to obtain mesozooplankton abundance and size (Bachiller \& Fernandes 2011, Bachiller et al. 2012). Each zooplankton individual was automatically counted and measured. Mesozooplankton counts were standardized by the software to number of individuals per $\mathrm{m}^{3}$. Detailed analyses of larval fish and zooplankton distribution and abundance from this survey are found in Rodriguez et al. (2015a), and Rodriguez et al. (2015b).

\section{Acoustic data}

During the survey, acoustic backscattering was continuously recorded by an EK60 echo sounder operating with $18,38,70,120$ and $200 \mathrm{kHz}$ split-beam, hull-mounted transducers. A beam width of $7^{\circ}$ was common for all frequencies, except $18 \mathrm{kHz}$, with an $11^{\circ}$ beam. A transmitted pulse 
length of 1.024 ms was employed in all frequencies. The acoustic system was calibrated before the survey following the standard target method (Foote et al. 1987) with a $38.1 \mathrm{~mm}$ diameter tungstencarbide sphere positioned under the extended dropkeel.

The acoustic signals were analyzed and integrated by the postprocessing system Echoview v4.20. The volume backscatter threshold $\left(S v, d B\right.$ re $\left.1 \mathrm{~m}^{-1}\right)$ was $-75 \mathrm{~dB}$. In order to analyze the relationship between the volume scattering intensities with net catches, the sampling gear

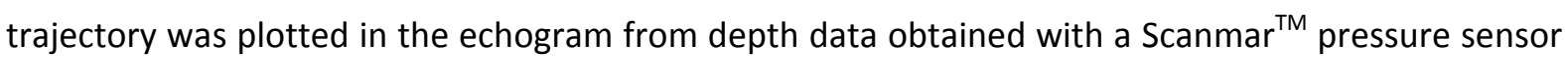
attached to the MultiNet sampler. Real-time depth data registered by this sensor was transferred by acoustic telemetry to hull-mounted hydrophones, allowing to monitor the net's path, and to send the datagram via a LAN port to the ER-60 echo sounder. A specific software routine ('El Gregoriano', developed at the Centre Oceanogràphic de les Balears by one of the authors, J. Miquel) was used to represent the gear trajectory over the echograms in the postprocessing software. The datagrams from the depth sensor towed behind the ship were thus matched to the echograms, with a file structure compatible with the Echoview version used in this work. Finally, from the gear trajectory line represented in the echograms, virtual parallel lines were generated by the Echoview software, defining the areas employed for subsequent analysis (Fig. 2).

Before any processing of the echograms, background noise was removed using the Echoview Data Generator Operator. This operator amplified the background noise at $1 \mathrm{~m}$, i.e., the initial $\mathrm{S}_{\mathrm{v}}$ value of noise, according to the formula of time-varied-gain (TVG):

(1) $20 \times \log \times R+2 \times \alpha \times R$ where $R$ is the depth $(\mathrm{m})$ and $\alpha$ is the attenuation coefficient. To calculate the background noise at $1 \mathrm{~m}$, a region with exclusive background noise was integrated, and its average $\mathrm{S}_{\mathrm{v}}$ was estimated. The TVG amplification was subtracted from the $20 \log R$ echograms. During the survey, the average of noise level at $1 \mathrm{~m}$ was: $-122.9 \pm 3.9$ (mean \pm SD), $-128.2 \pm 4.9,-137.9 \pm 4.9,-140.7 \pm$ 5.2 and $-141.1 \pm 4.6 \mathrm{~dB}$ at frequency of $18,38,70,120$ and $200 \mathrm{kHz}$, respectively. 
To analyze the spatial distribution of echo intensities at the five frequencies employed, echo integration measurements in terms of the Nautical Area Scattering Coefficient (NASC in $\mathrm{m}^{2} \cdot \mathrm{nm}^{-2}$, (MacLennan et al. 2002)) were determined during the scrutinizing process of the echograms (Foote et al. 1991) over regions delimiting aggregations characterized as fish larvae. This characterization was based on (i) the frequency response results from the acoustic-biological data relationships; (ii) the output from the Andreeva model, both approaches described below; and (iii) the aggregation's shape and vertical distribution. The NASC values were averaged at EDSU (Elementary Distance Sampling Unit, (MacLennan et al. 2002)) of $1 \mathrm{nmi}$, and interpolated between sampling transect over the study area and mapped with Surfer ${ }^{\circledR}$ (Golden Software, Inc.).

The comparative analysis of the horizontal distribution of fish larvae densities and acoustic backscattering at the frequencies used was done considering only fish larvae with a functional swimbladder. In order to estimate the density of larvae with developed swimbladders, 7 taxa with swimbladders (Micromesistius poutassou, Merluccius merluccius, Trisopterus minutus, Maurolicus muelleri, Sardina pilchardus, Trachurus trachurus and Callionymus spp.) were selected between the nine most abundant taxa, which represent $72 \%$ of the total fish larval community. Only hauls where the average length of larvae exceeded that of size of the initial development of the swimbladder were included in the analysis. These sizes were taken from the literature whenever possible: $M$. merluccius (Bjelland \& Skiftesvik 2006), S. pilchardus (Ré 1986), M. muelleri (Ozawa 1976) and T. trachurus (Russell 1976). In species for which no references were found, the minimum length was taken as the mean of the length-range in the samples.

Variations in the vertical distribution patterns of larval aggregations were examined only at 38 and $70 \mathrm{kHz}$. In order to do so, the echograms obtained along the survey track were divided into layers of $10 \mathrm{~m}$ depths, and also averaged over EDSU of $1 \mathrm{nmi}$. The depth of layers with maximum mean $S_{v}$ at each averaging point provided a reference of the depth of the aggregation core during day and night hours. 

were fitted using R software (R Development Core Team 2014). Fish larvae abundances were log10transformed prior to analysis, to meet the assumptions of linear regression. The density of fish larvae at each net/depth was compared with the $S_{v}$ extracted from echogram regions defined following the opening-closing time at each level. Regions were extended four meters in height $(2 \mathrm{~m}$ above and $2 \mathrm{~m}$ below the net track).

For the most dominant species, $M$. poutassou, the size of gas-bearing fish larvae at resonance was estimated following the methodology detailed by Álvarez-Colombo et al. (2011). It was performed considering the acoustic resonance response of small bubbles at the frequency range employed (Gjøsæter 1977, Kloser et al. 2002, Davison et al. 2015). The size and depth at resonance for the five frequencies employed during the survey were determined in two steps: first, the Andreeva (1964) model was used to infer the size of resonant swimbladders, and then to estimate the corresponding larvae lengths we used the swimbladder's size to larval total length relationship established for the Argentine hake (M. hubbsi) by Álvarez-Colombo et al. (2011), assuming a similar development and inflation process on the initial life stages of these two gadiformes.

\section{Results}

\section{Biological sampling}

Larval density pooled for all fish species ranged from 8.26 to 14400.00 larvae $\cdot 1000 \mathrm{~m}^{-3}$. A total of 62 taxa (59 species and 3 genera) of larvae of 28 families were caught. The most abundant larval fish species were $M$. poutassou (accounting for $32.61 \%$ of the total larval fish density), Scomber scombrus (19.48\%), T. minutus (4.49\%), S. pilchardus (3.98\%) M. merluccius (3.55\%), and T. trachurus (2.69\%). Larvae of M. poutassou and M. merluccius were widespread over the study area, while larvae of S. pilchardus, S. scombrus, $T$. trachurus and T. minutus were restricted to the shelf region (Fig. 3). Length frequency distribution of these species is shown in Fig. 4 . Up to $78.7 \%$ of the total larval fish concentration was found in the upper $60 \mathrm{~m}$ of the water column, and $92.5 \%$ in the 
upper $100 \mathrm{~m}$. A more detailed description of the larval fish community composition and structure, horizontal and vertical distribution and diel movements of fish larvae are found in Rodriguez et al. (2015a) and Rodriguez et al. (2015b).

\section{Spatial distribution}

Zooplanktonic aggregations were detected along the sampling transects. They were particularly intense at depths lower than $100 \mathrm{~m}$, at frequencies of 38 and $70 \mathrm{kHz}$, being higher than the acoustic threshold used during the survey $(-75 \mathrm{kHz})$. The average $S_{v}$ detected at $18-200 \mathrm{kHz}$ ranged from -70.6 to $-64.8 \mathrm{~dB}$. The horizontal distribution of the densities of fish larvae with a functional swimblader estimated from the multinet catches was compared with the acoustic backscatter distribution at all frequencies analyzed. Density of fish larvae increased from south to north (Fig. 5). The main aggregation of fish larvae occurred in the northernmost area, followed by a relatively high larval fish density off A Coruña (see Fig. 1 for locations). Acoustic backscatter and swimbladdered larval fish density showed similar distribution patterns for all frequencies (Fig. 5). However, the best correspondences between acoustic sizes and the main larval fish agreggation was found at 38 and $70 \mathrm{kHz}$ (Fig. 5c,d), while less similarity was found considering the other three frequencies, particularly at 120 and $200 \mathrm{kHz}$ (Fig. 5b,e,f).

Daytime and nighttime vertical distribution of larval fish aggregations in 38 and $70 \mathrm{kHz}$ echograms did not appreciably differ, particularly at $70 \mathrm{kHz}$. At $38 \mathrm{kHz}$, the maximum $\mathrm{S}_{\mathrm{v}}$ values over the surveyed area were found at depths ranging between 20 and $130 \mathrm{~m}$ during daylight, and between 10 and $110 \mathrm{~m}$ depth at night (Fig. 6). However, $\mathrm{S}_{v}$ was mostly confined between 20 and 70 $\mathrm{m}$ in coincidence with larval fish concentrations in net samples. A wider dispersion of the maximum acoustic values through the water column during day, and a tendency to concentrate in the shallower layers during the night, was also observed.

The depth-compensated noise levels for the frequency range used, estimated from the average recorded noise levels at $1 \mathrm{~m}$, reached the mean sacttering levels of the plankton layers at a 
minimum depth of $190 \mathrm{~m}$ for $200 \mathrm{kHz}$, and a maximum depth of $480 \mathrm{~m}$ for $38 \mathrm{kHz}$ (190 and $290 \mathrm{~m}$ depth for the threshold of $-75 \mathrm{~dB}$ employed, respectively). Given that those depths are greater than the maximum depth of the studied acoustic layers, the noise contribution to plankton-scattering levels was considered negligible.

\section{Relating biological sampling with acoustics}

The scatterplots and linear relationships between the acoustic backscattered energy relationship between $S_{v}$ and density of fish larvae at all frequencies (Table 1 ). The best fit was obtained at $70 \mathrm{kHz}\left(\mathrm{R}^{2}=0.577\right)$. The regression model, including fish larvae and zooplankton abundances, reduced only slighlty the AIC and did not increase significantly the coefficients of determination (Table 1), and actually the zooplankton contribution was not significant at all frequencies $(p>0.07)$.

To check that swimbladders of fish larvae produced the backscatter detected by the echo sounder, we compared the $S_{v}$ values with the density of all fish species that develop swimmbladders (Table 1). The regressions at each frequency yielded virtually the same results as in previous analyses and, likewise, the zooplankton abundance was not significant. Since swimbladder inflates some time after hatching, and most of the larvae collected were small (Fig. 4), we assessed the impact of larval size on the relationship between $S_{v}$ values and the density of the most abundant species, $M$. poutassou, which was also well distributed over the studied area. The linear fit improved at 38, 70 and $120 \mathrm{kHz}$ when hauls with average larval length smaller than $3.0 \mathrm{~mm}$ were removed (Table 2). Thus, excluding those hauls, the coefficient of determination at 70 and $120 \mathrm{kHz}$ was 0.556 and 0.509 , respectively. When hauls with average larval length smaller than $3.5 \mathrm{~mm}$ were excluded, the coefficient of determination at $38 \mathrm{KH}$ was 0.428 . A possible explanation may be that an inflated, i.e., functional swimbladder, can be disregarded in M. poutassou larve smaller than $3.0-3.5 \mathrm{~mm}$. The relationships slightly improved with increasing larval length at $200 \mathrm{kHz}$, whereas at $18 \mathrm{kHz}$, the linear fit was not significant in any case. 

backscattering (in $\mathrm{S}_{\mathrm{v}}$ ) was lower at all frequencies, not only for the total zooplankton but also for most groups (Table 3). The best fit was found for chaetognats and polychaetes, which reached an $\mathrm{R}^{2}$ higher than 0.35 at 38 (in the case of chaetognats) and $70 \mathrm{kHz}$ (in both groups). frequencies of $120-200 \mathrm{kHz}$, resonance would be expected in larvae smaller than $3 \mathrm{~mm}$, for which an inflated swimbladder in $M$. pottasou was not considered. At the lowest frequency employed, $18 \mathrm{kHz}$, the models predict resonance from larvae of $10 \mathrm{~mm}$ and larger, which were not found in this study. In accordance, the $18 \mathrm{kHz}$ echograms did not show significant echotraces in correspondence with larval fish catches, likely because the survey was completed at the beginning of the spawning season, supported by the fact that most of the larvae were in early posthatch stages.

\section{Discussion}

Potential use of acoustic techniques and limitations

This is the first acoustic study on the larval community in the Galician waters. In this paper, ichthyoplankton methodology, with the results from an acoustic survey at five frequencies. Because the acoustic backscattered energy is proportional to the number and/or size of swimbladders in fish

291 (or gas inclusions in zooplankton), we have compared fish and zooplankton densities instead of comparing scatters with biomass of the individuals. The regression analyses revealed that the acoustic response at the frequency range of $38-120 \mathrm{kHz}$ were effective to detect larval fish aggregations. However, the predicted acoustic resonance at larval size and depth show that the 120 
seems to be in accordance with the lack of agreement between the larvae abundance and the acoustic response at this frequency observed in the spatial distribution.

There are a few examples of the use of acoustics to detect fish larvae aggregations at the acoustic range employed for adult fish assessments. The importance of the $38 \mathrm{kHz}$ frequency for detecting M. hubbsi larval aggregations from echograms has been previously highlighted (ÁlvarezColombo et al. (2011). Rudstam et al. (2002) found that the assessment of fish larvae smaller than 15 $\mathrm{mm}$ at $70 \mathrm{kHz}$ was obscured due to the presence of invertebrate targets and noise. Our results indicate that the contribution of zooplankton (other than fish larvae) to total scattering at $18-120$

$\mathrm{kHz}$ range in the acoustic regions corresponding with the net path was negligible, except for several groups of fluid-like zooplankton, such as chaetognats and polychaetes. Also, the contribution of background noise was found to be low at the entire frequency range and depths analyzed.

The relationships between acoustic signals and M. poutassou larvae densities improved considerably when the stations with smaller average larval length were removed from the analyses. The best fits were found when considering sizes larger than $3.0-3.5 \mathrm{~mm}$, possibly related to the development of a functional swimbladder and the highest abundances at these sizes. This clearly indicates that smaller larvae did not contribute significantly to the recorded acoustic echoes. On the other hand, when considering hauls with an average size larger than $3.0-3.5 \mathrm{~mm}$, the coefficients of determination were lower. This was likely due to the low abundance at these sizes, and then the residual noise or the contribution to total backscattering from other organisms may contribute more to the acoustic signals.

The time, and hence larval size, of the swimbladder's first inflation is species-specific. For example, swimbladder formation in T. trachurus occurs at $4 \mathrm{~mm}$ standard length (Russell 1976), in $E$. encrasicolus at $7 \mathrm{~mm}$, and in S. pilchardus at $10 \mathrm{~mm}$ (Ré 1986). Thus, it is critical to study the ontogeny of swimbladder inflation for the construction of backscattering models used to interpret acoustic surveys (Davison 2011). Our results suggest that the development of a functional swimbladder in M. poutassou occurs at a length of 3.0-3.5 mm standard length, slightly smaller than 
that observed for other Gadiformes, like M. hubbsi (Álvarez-Colombo et al. 2011) and M. merluccius (Bjelland \& Skiftesvik 2006).

As contrasting examples, while the detection and analysis of $M$. hubbsi larvae in the Argentine shelf is carried out in a rather straightforward manner, given the low larval species diversity and the enormous abundances of all larval stages of $M$. hubbsi during its reproductive season (Álvarez-Colombo et al. 2011), in Galician waters, this constitutes a complex task because of the relatively high diversity of the larval fish assemblage in this region. Nevertheless, the high abundance of resonant fish larvae, particularly M. potassou, provided an opportunity to isolate and map the spatial distribution of their aggregations over the entire survey.

The scrutinizing process employed to interpret the survey datasets implies the fact that the user, not the system, makes all the important decisions in the course of interpreting the data, as denoted by (Foote et al. 1991). This methodology is inherently subjective, as this involves making decisions about the nature of scatterers from an underdimensioned graphical representation, and based on the operator experience (Foote et al. 1991, Godø et al. 2004). However, auxiliary data provided by the postprocessing software (TS distribution, NASC relative frequency response) and others features contribute to the interpretation criterion.

Although the MultiNet MiDi allows to study the vertical distribution of fish larvae (Rodriguez et al. 2015b), some degree of avoidance of this sampler from the larger fraction of the actual larvae length range is normally assumed. However, the survey was completed at the beginning of the spawning season, with most of the caught larvae being in early posthatch stages. Consequently, most larvae caught in this study were early larvae with little ability to avoid the net. Also, our models predicted a resonance from larvae of $10 \mathrm{~mm}$ and larger at the frequency of $18 \mathrm{kHz}$, but the related echograms did not show significant echo traces in correspondence with larval fish catches. This suggests that larvae of these sizes were not present in the study area at the time of the sampling.

In environments characterized by multispecific assemblages of acoustic targets, detecting and isolating the different acoustic signals requires advanced multifrequency acoustic techniques, 
allowing for the classification of echotraces and scattering layers into species, or species groups, with distinct scattering properties (Korneliussen \& Ona 2002, Korneliussen \& Ona 2003). The contribution of acoustic targets, other than fish larvae, to the total scattering recorded at the different frequencies employed has not been accomplished in this preliminary study, focused on the detection of resonant fish larvae at a frequency range where the contribution of other zooplankton taxa was negligible. However, multifrequency acoustic techniques should be included in future research to study in detail the complexity of the zooplankton community structure in Galician waters.

This study emphasizes the opportunity for the use of echo-sounding data obtained at frequencies routinely used during research cruises, and also during vessels of opportunity operations, which could extend the spatial and temporal coverage of acoustic data collection beyond those of research vessel programs (Dalen \& Karp 2007). Also, the acoustic characterization of fish larvae aggregations at narrow band, commonly employed frequencies provide an available existent acoustic databases.

\section{Implications of the results in recruitment and fisheries management}

The poorly defined stock-recruitment relationship is a cornerstone of fisheries assessment and management via projected stock development, and is inherently found in biological reference points (Saborido-Rey \& Trippel 2013). The understanding of recruitment variability has been improved in recent decades through the concept of stock reproductive potential (Trippel 1999, Saborido-Rey \& Trippel 2013) intimately linked to larval survivorship, through the parental effects on larval viability (Kamler 2005, Green 2008). Field applications of these results have been prevented by

371 the inherent difficulty in getting proper data on larval distribution and abundance, to conduct correlation analysis (Lo et al. 2009). Yet, recruitment in fish populations is largely determined during the early life-history stages by a combination of factors operating over multiple spatiotemporal 
scales, such as predation, starvation, and spatial mismatch with appropriate areas (Leggett \& Deblois 1994, Subbey et al. 2014, and references therein). Despite some advances, it remains difficult to obtain accurate and precise estimates of abundance of early life stages of fishes, their predators, and prey, at the spatial scales over which they interact (Houde 2009).

With the potential of the acoustic methodology, improved studies can be conducted to test with highest confidence the enduring theories and hypothesis on recruitment fluctuations (reviewed by Houde (2009) and Hare (2014)), and, in particular (i) to observe the density-dependent interactions between fish larvae and their predators and prey; (ii) to determine the drivers and factors affecting movement and distributional patterns of fish larvae; (iii) building and assessing quantitative drift models, pairing with the high-resolution ocean circulation models developed in past decades (Staaterman \& Paris 2014); (iv) to understand the underlying processes determining the timing and duration of the recruitment interval, which is critical to assess the impact of specific mortality; ( $v$ ) to study habitat selection and, consequently, a better estimation of recruitment at the stage of presettlement and, finally (vi) to estimate the spawning biomass using the larval production method, especially when fish eggs are not available or accessible, or they are difficult to identify (Lo et al. 2009).

In summary, this study shows that larval aggregations in Galician waters can be detected and quantified with a relative abundance index derived from acoustic methods. Abundance of swimbladder larval fish estimated with acoustics was comparable, and correlated with that obtained with conventional sampling methods, particularly at 38 and $70 \mathrm{kHz}$. Thus, in this period of technological advances, acoustics point to being a useful tool to overcome difficulties associated with larval ecology and fish recruitment.

\section{Acknowledgments}

The authors thank the assistance of the crew of RV Cornide de Saavedra and all the participants in the Cramer 0312 cruise. This work was supported by the project CRAMER (CTM2010- 
400

401

402

403

404

405

406

407

408

409

410

411

412

413

414

415

416

417

418

419

420

421

21856-CO3), funded by the Spanish Ministry of Economy and Competitiveness and by the project ECOPREGA (10MMA602021PR), funded by the Regional Government of Galicia (Xunta de Galicia). We are also grateful to the two anonymous referees for their constructive comments on the manuscript.

\section{References}

Aiken CM, Navarrete SA (2011) Environmental fluctuations and asymmetrical dispersal: generalized stability theory for studying metapopulation persistence and marine protected areas. Mar Ecol Prog Ser 428:77-88

Almany GR, Connolly SR, Heath DD, Hogan JD, Jones GP, McCook L, Mills M, Pressey RL, Williamson DH (2009) Connectivity, biodiversity conservation and the design of marine reserve networks for coral reefs. Coral Reefs 28:339-351

Álvarez-Colombo G, Dato C, Macchi GJ, Palma E, Machinandiarena L, Christiansen HE, Betti P, Derisio C, Martos P, Castro-Machado F, Brown D, Ehrlich M, Mianzan H, Acha EM (2011) Distribution and behavior of Argentine hake larvae: Evidence of a biophysical mechanism for self-recruitment in northern Patagonian shelf waters. Cienc Mar 37:633-657

Álvarez P, Chifflet M (2012) The fate of eggs and larvae of three pelagic species, mackerel (Scomber scombrus), horse mackerel (Trachurus trachurus) and sardine (Sardina pilchardus) in relation to prevailing currents in the Bay of Biscay: Could they affect larval survival? Sci Mar 76:573-586

Andreeva IB (1964) Scattering of sound by air bladders of fish in deep sound-scattering ocean layers. Sov Phys Acoust 10:17-20

Bachiller E, Fernandes JA (2011) Zooplankton Image Analysis Manual: automated identification by means of scanner and digital camera as imaging devices. Rev Invest Mar 18:16-37

Bachiller E, Fernandes JA, Irigoien X (2012) Improving semiautomated zooplankton classification using an internal control and different imaging devices. Limnol Oceanogr:Methods 10:1-9

Barkley RA (1972) Selectivity of towed-net samplers. Fish Bull 70:799-820 
Beaugrand G, Brander KM, Lindley JA, Souissi S, Reid PC (2003) Plankton effect on cod recruitment in the North Sea. Nature 426:661-664

Becker BJ, Levin LA, Fodrie FJ, McMillan PA (2007) Complex larval connectivity patterns among marine invertebrate populations. Proc Natl Acad Sci USA 104:3267-3272

Bjelland RM, Skiftesvik AB (2006) Larval development in European hake (Merluccius merluccius L.) reared in a semi-intensive culture system. Aquacult Res 37:1117-1129

Bonanno A, Goncharov S, Mazzola S, Popov S, Cuttitta A, Patti B, Basilone G, Di Nieri A, Patti C, oceanography in the Cape Passero area (Strait of Sicily). Chem Ecol 22:S265-S273

Cowen RK, Paris CB, Srinivasan A (2006) Scaling of connectivity in marine populations. Science 311:522-527

Cowen RK, Sponaugle S (2009) Larval dispersal and marine population connectivity. Annu Rev Mar Sci 1:443-466

Dalen J, Karp WA (2007) Collection of acoustic data from fishing vessels. ICES Coop Res Rep № 287

Davison P (2011) The specific gravity of mesopelagic fish from the northeastern Pacific Ocean and its implications for acoustic backscatter. ICES J Mar Sci 68:2064-2074

Davison P, Lara-Lopez A, Koslow JA (2015) Mesopelagic fish biomass in the southern California current ecosystem. Deep-Sea Res Pt II 112:129-142

Fariña AC, Freire J, González-Gurriarán E (1997) Demersal fish assemblages in the Galician continental shelf and upper slope (NW Spain): spatial structure and long-term changes. Estuar Coast Shelf Sci 44:435-454

Foote KG, Knudsen HP, Korneliussen RJ, Nordbø PE, Røang K (1991) Postprocessing system for echo sounder data. J Acoust Soc Am 90:37-47

Foote KG, Knudsen HP, Vestnes G (1987) Calibration of acoustic instruments for fish density estimation : a practical guide. ICES Coop Res Rep № 144:71 pp 
Gjøsæter J (1977) Aspects of the distribution and ecology of the Myctophidae from the Western and Northern Arabian Sea. Indian Ocean Fishery and Development Programme : Pelagic Fish Assessment Survey North Arabian Sea

Godø OR, Handegard NO, Browman HI, Macaulay GJ, Kaartvedt S, Giske J, Ona E, Huse G, Johnsen E (2014) Marine ecosystem acoustics (MEA): quantifying processes in the sea at the spatiotemporal scales on which they occur. ICES J Mar Sci 71:2357-2369

Godø OR, Hjellvik V, Greig T, Beare D (2004) Can subjective evaluation of echograms improve correlation between bottom trawl and acoustic densities? ICES CM 2004 R:23

God $\varnothing$ OR, Patel R, Pedersen G (2009) Diel migration and swimbladder resonance of small fish: some implications for analyses of multifrequency echo data. ICES J Mar Sci 66:1143-1148

Green BS (2008) Maternal effects in fish populations. In: David WS (ed) Adv Mar Biol, Book 54. Academic Press, p 1-105

Hare JA (2014) The future of fisheries oceanography lies in the pursuit of multiple hypotheses. ICES J Mar Sci 71:2343-2356

Hernandez Jr FJ, Carassou L, Muffelman S, Powers SP, Graham WM (2011) Comparison of two plankton net mesh sizes for ichthyoplankton collection in the northern Gulf of Mexico. Fish Res 108:327-335

Hjort J Fluctuations in the great fisheries of northern Europe viewed in the light of biological research. Proc Rapports et Procés - Verbaux des Réunions du Conseil International pour I'Exploration de la Mer. ICES, p 228

Houde ED (2008) Emerging from Hjort's shadow. J Northw Atl Fish Sci 41:53-70

Houde ED (2009) Recruitment Variability. In: Jakobsen T, Fogarty MJ, Megrey BA, Moksness E (eds) Fish reproductive biology: implications for assessment and management. Wiley-Blackwell, Oxford, UK, p 91-171 
Ibaibarriaga L, Irigoien X, Santos M, Motos L, Fives JM, Franco C, Lago De Lanzós A, Acevedo S, Bernal M, Bez N, Eltink G, Farinha A, Hammer C, Iversen SA, Milligan SP, Reid DG (2007) Egg and larval distributions of seven fish species in north-east Atlantic waters. Fish Oceanogr 16:284-293

Johnson DL, Morse WW (1994) Net extrusion of larval fish: correction factors for 0.333 mm versus $0.505 \mathrm{~mm}$ mesh bongo nets. NAFO Sci Coun Studies 20:85-92

Kamler E (2005) Parent-egg-progeny relationships in teleost fishes: An energetics perspective. Rev Fish Biol Fish 15:399-421

Kloser RJ, Ryan T, Sakov P, Williams A, Koslow JA (2002) Species identification in deep water using multiple acoustic frequencies. Can J Fish Aquat Sci 59:1065-1077

Korneliussen RJ, Ona E (2002) An operational system for processing and visualizing multi-frequency acoustic data. ICES J Mar Sci 59:293-313

Korneliussen RJ, Ona E (2003) Synthetic echograms generated from the relative frequency response. ICES J Mar Sci 60:636-640

Le Corre N, Guichard F, Johnson LE (2012) Connectivity as a management tool for coastal ecosystems in changing oceans. In: Marcelli M (ed) Oceanography. INTECH Open Access Publisher, p 235-258

Leggett WC, Deblois E (1994) Recruitment in marine fishes: Is it regulated by starvation and predation in the egg and larval stages? Neth J Sea Res 32:119-134

Leslie JK, Timmins CA (1989) Double nets for mesh aperture selection and sampling in ichthyoplankton studies. Fish Res 7:225-232

Lo NCH, Smith PE, Takahashi M (2009) Egg, larval, and juvenile surveys. In: Jakobsen T, Fogarty MJ, Megrey BA, Moksness E (eds) Fish reproductive biology: implications for assessment and management. Wiley-Blackwell, Oxford, UK, p 207-229

MacLennan DN, Fernandes PG, Dalen J (2002) A consistent approach to definitions and symbols in fisheries acoustics. ICES J Mar Sci 59:365-369

MacLennan DN, Holliday DV (1996) Fisheries and plankton acoustics: past, present, and future. ICES J Mar Sci 53:513-516 
501

502

503

504

505

506

507

508

509

510

511

512

513

514

515

516

517

518

519

520

521

522

523

524

525

McClain CR, Chao S-Y, Atkinson LP, Blanton JO, De Castillejo F (1986) Wind-driven upwelling in the vicinity of Cape Finisterre, Spain. J Geophys Res:Oceans 91:8470-8486

Misund OA (1997) Underwater acoustics in marine fisheries and fisheries research. Rev Fish Biol Fish 7:1-34

Miyashita K (2003) Diurnal changes in the acoustic-frequency characteristics of Japanese anchovy (Engraulis japonicus) post-larvae "shirasu" inferred from theoretical scattering models. ICES J Mar Sci 60:532-537

Motos L, Uriarte A, Valencia V (1996) The spawning environment of the Bay of Biscay anchovy (Engraulis encrasicolus L.). Sci Mar 60:117-140

Nielsen TG, Munk P (1998) Zooplankton diversity and the predatory impact by larval and small juvenile fish at the Fisher Banks in the North Sea. J Plankton Res 20:2313-2332

Ozawa T (1976) Early life history of the Gonostomatid fish, Pollichthys mauli, in the oceanic region off Southern Japan. Jap J Ichthyol 23:43-54

Pusack TJ, Christie MR, Johnson DW, Stallings CD, Hixon MA (2014) Spatial and temporal patterns of larval dispersal in a coral-reef fish metapopulation: evidence of variable reproductive success. Mol Ecol 23:3396-3408

R Development Core Team (2014) R: A language and environment for statistical computing. R Foundation for statistical computing. http://www.R-project.org

Ré P (1986) Otolith microstructure and the detection of life history events in sardine and anchovy larvae. Ciênc Biol Ecol Syst 6:9-17

Rodriguez JM, Cabrero A, Gago J, Garcia A, Laiz-Carrion R, Piñeiro C, Saborido-Rey F (2015a) Composition and structure of the larval fish in the NW Iberian upwelling system during the winter mixing period. Mar Ecol Prog Ser 533:245-260

Rodriguez JM, Cabrero A, Gago J, Guevara-Fletcher C, Herrero M, Hernandez de Rojas A, Garcia A, Laiz-Carrion R, Vergara AR, Alvarez P, Piñeiro C, Saborido-Rey F (2015b) Vertical distribution and 
migration of fish larvae in the NW Iberian upwelling system during the winter mixing period: implications for cross-shelf distribution Fish Oceanogr 24:274-290

Rudstam LG, VanDeValk AJ, Scheuerell MD (2002) Comparison of acoustic and Miller high-speed sampler estimates of larval fish abundance in Oneida Lake, New York. Fish Res 57:145-154

Russell FS (1976) The eggs and planktonic stages of British marine fishes. Academic Press, London

Staaterman E, Paris CB (2014) Modelling larval fish navigation: the way forward. ICES J Mar Sci 71:918-924 Nematoscelis megalops. Fish Bull 80:75-91

Stratoudakis Y, Bernal M, Uriarte A (2004) The DEPM estimation of spawning-stock biomass for sardine and anchovy. ICES Coop Res Rep № 268:91 pp

Subbey S, Devine JA, Schaarschmidt U, Nash RDM (2014) Modelling and forecasting stockrecruitment: current and future perspectives. ICES J Mar Sci 71:2307-2322

Surís-Regueiro JC, Santiago JL (2014) Characterization of fisheries dependence in Galicia (Spain). Mar Policy 47:99-109

Theilacker GH (1980) Changes in body measurements of larval northern anchovy, Engraulis mordax, and other fishes due to handling and preservation. Fish Bull 78:685-692

Trippel EA (1999) Estimation of stock reproductive potential: history and challenges for Canadian Atlantic gadoid stock assessments. J Northw Atl Fish Sci 25:61-82

Van der Lingen CD, Huggett JA (2003) The role of ichthyoplankton surveys in recruitment research and management of South African anchovy and sardine. In: Browman HI, Skiftesvik AB (eds) The Big Fish Bang: Proceedings of the 26th Annual Larval Fish Conference. Institute of Marine Research, Bergen, Norway.

Wiebe PH, Boyd SH, Davis BM, Cox JL (1982) Avoidance of towed nets by the euphausiid 
553 Table 1. GLM results (Akaike information criteria and coefficient of determination) comparing 554 models for testing the relationship between the acoustic backscatter $\left(\mathrm{S}_{\mathrm{v}}\right)$ and all fish larvae 555 abundance (FISH), abundance of fish larvae with functional swimbladder (SWFISH), and zooplankton 556 other than fish larvae (ZOO), for each of the frequencies analyzed. $p$-value $<0.001$ for all cases.

557

\begin{tabular}{|c|c|c|c|c|c|c|c|c|c|c|}
\hline \multirow[b]{3}{*}{ Model } & \multicolumn{10}{|c|}{ Frequency } \\
\hline & \multicolumn{2}{|c|}{$18 \mathrm{kHz}$} & \multicolumn{2}{|c|}{$38 \mathrm{kHz}$} & \multicolumn{2}{|c|}{$70 \mathrm{kHz}$} & \multicolumn{2}{|c|}{$120 \mathrm{kHz}$} & \multicolumn{2}{|c|}{$200 \mathrm{kHz}$} \\
\hline & AIC & $\mathrm{R}^{2}$ & AIC & $\mathrm{R}^{2}$ & AIC & $\mathrm{R}^{2}$ & AIC & $\mathrm{R}^{2}$ & AIC & $\mathrm{R}^{2}$ \\
\hline $\mathrm{S}_{v} \sim \mathrm{FISH}$ & 1893 & 0.130 & 1878 & 0.489 & 1788 & 0.577 & 1724 & 0.463 & 1814 & 0.342 \\
\hline $\mathrm{S}_{v} \sim \mathrm{FISH}+\mathrm{ZOO}$ & 1861 & 0.132 & 1845 & 0.489 & 1755 & 0.577 & 1691 & 0.473 & 1773 & 0.362 \\
\hline $\mathrm{S}_{v} \sim \mathrm{SWFISH}$ & 1697 & 0.067 & 1660 & 0.381 & 1567 & 0.515 & 1520 & 0.410 & 1574 & 0.291 \\
\hline $\mathrm{S}_{Y} \sim \mathrm{SWFISH}+\mathrm{ZOO}$ & 1668 & 0.083 & 1624 & 0.398 & 1532 & 0.527 & 1492 & 0.428 & 1540 & 0.331 \\
\hline
\end{tabular}

558 Table 2. Coefficients of determination (adjusted $R^{2}$ ) and $p$-values from the scatterplots of acoustic

559 backscatter (in $\mathrm{S}_{\mathrm{v}}$ ) versus Micromesistius poutassou larvae abundance (log10-transformed)

560 estimated by Multinet Midi trawl. The inclusion or exclusion of the different hauls in these lineal

561 regression analyses was based on the average larval lengths of $M$. poutassou for each haul.

\begin{tabular}{|c|c|c|c|c|c|c|c|c|c|c|}
\hline \multirow{3}{*}{$\begin{array}{l}\text { Micromessistius } \\
\text { poutassou }\end{array}$} & \multicolumn{10}{|c|}{ Frequency } \\
\hline & \multicolumn{2}{|c|}{$18 \mathrm{kHz}$} & \multicolumn{2}{|c|}{$38 \mathrm{kHz}$} & \multicolumn{2}{|c|}{$70 \mathrm{kHz}$} & \multicolumn{2}{|c|}{$120 \mathrm{kHz}$} & \multicolumn{2}{|c|}{$200 \mathrm{kHz}$} \\
\hline & $\mathrm{R}^{2}$ & $p$-value & $\mathrm{R}^{2}$ & $\mathrm{p}$-value & $\mathrm{R}^{2}$ & $\mathrm{p}$-value & $\mathrm{R}^{2}$ & $\mathrm{p}$-value & $\mathrm{R}^{2}$ & $p$-value \\
\hline Total larvae & 0.003 & 0.245 & 0.223 & $<0.001$ & 0.407 & $<0.001$ & 0.349 & $<0.001$ & 0.227 & $<0.001$ \\
\hline Larvae $\geq 2.0 \mathrm{~mm}$ & 0.002 & 0.275 & 0.207 & $<0.001$ & 0.397 & $<0.001$ & 0.345 & $<0.001$ & 0.232 & $<0.001$ \\
\hline Larvae $\geq 2.5 \mathrm{~mm}$ & 0.003 & 0.257 & 0.295 & $<0.001$ & 0.495 & $<0.001$ & 0.464 & $<0.001$ & 0.333 & $<0.001$ \\
\hline Larvae $\geq 3.0 \mathrm{~mm}$ & 0.016 & 0.123 & 0.409 & $<0.001$ & 0.526 & $<0.001$ & 0.503 & $<0.001$ & 0.314 & $<0.001$ \\
\hline Larvae $\geq 3.5 \mathrm{~mm}$ & -0.003 & 0.378 & 0.428 & $<0.001$ & 0.440 & $<0.001$ & 0.414 & $<0.001$ & 0.251 & $<0.001$ \\
\hline Larvae $\geq 4.0 \mathrm{~mm}$ & -0.020 & 0.945 & 0.352 & $<0.001$ & 0.315 & $<0.001$ & 0.260 & $<0.001$ & 0.211 & $<0.001$ \\
\hline Larvae $\geq 4.5 \mathrm{~mm}$ & -0.021 & 0.609 & 0.379 & $<0.001$ & 0.349 & $<0.001$ & 0.284 & $<0.001$ & 0.321 & $<0.001$ \\
\hline
\end{tabular}

562

563 Table 3. Coefficients of determination (adjusted $R^{2}$ ) and $p$-values from the scatterplots of acoustic 564 backscatter (in $\mathrm{S}_{\mathrm{v}}$ ) versus zooplankton (fish larvae excluded) abundance (log10-transformed), and the 565 abundance of the different groups of zooplankton individually analyzed. Abundances were 566 estimated from Multinet Midi trawl.

\begin{tabular}{|c|c|c|c|c|c|c|c|c|c|c|}
\hline & \multicolumn{10}{|c|}{ Frequency } \\
\hline & \multicolumn{2}{|c|}{$18 \mathrm{kHz}$} & \multicolumn{2}{|c|}{$38 \mathrm{kHz}$} & \multicolumn{2}{|c|}{$70 \mathrm{kHz}$} & \multicolumn{2}{|c|}{$120 \mathrm{kHz}$} & \multicolumn{2}{|c|}{$200 \mathrm{kHz}$} \\
\hline & $\mathrm{R}^{2}$ & $p$-value & $\mathrm{R}^{2}$ & $p$-value & $\mathrm{R}^{2}$ & $p$-value & $\mathrm{R}^{2}$ & $p$-value & $\mathrm{R}^{2}$ & $p$-value \\
\hline Total zooplankton & 0.050 & $<0.001$ & 0.194 & $<0.001$ & 0.171 & $<0.001$ & 0.132 & $<0.001$ & 0.119 & $<0.001$ \\
\hline Copepods & 0.023 & $<0.01$ & 0.141 & $<0.001$ & 0.117 & $<0.001$ & 0.091 & $<0.001$ & 0.079 & $<0.001$ \\
\hline Other crustaceans & 0.064 & $<0.001$ & 0.209 & $<0.001$ & 0.221 & $<0.001$ & 0.167 & $<0.001$ & 0.141 & $<0.001$ \\
\hline Cnidarids & -0.003 & 0.386 & 0.008 & 0.206 & 0.010 & 0.190 & -0.012 & 0.712 & -0.003 & 0.385 \\
\hline Moluscs & 0.114 & $<0.001$ & 0.249 & $<0.001$ & 0.218 & $<0.001$ & 0.170 & $<0.001$ & 0.169 & $<0.001$ \\
\hline Chaetognats & 0.058 & $<0.001$ & 0.375 & $<0.001$ & 0.359 & $<0.001$ & 0.273 & $<0.001$ & 0.243 & $<0.001$ \\
\hline Tunicates & 0.044 & $<0.001$ & 0.214 & $<0.001$ & 0.223 & $<0.001$ & 0.151 & $<0.001$ & 0.099 & $<0.001$ \\
\hline Polichaetes & 0.032 & 0.213 & 0.215 & $<0.05$ & 0.350 & $<0.01$ & 0.095 & 0.115 & 0.014 & 0.274 \\
\hline Eggs & 0.037 & $<0.01$ & 0.100 & $<0.001$ & 0.078 & $<0.001$ & 0.043 & $<0.001$ & 0.045 & $<0.001$ \\
\hline
\end{tabular}
567 


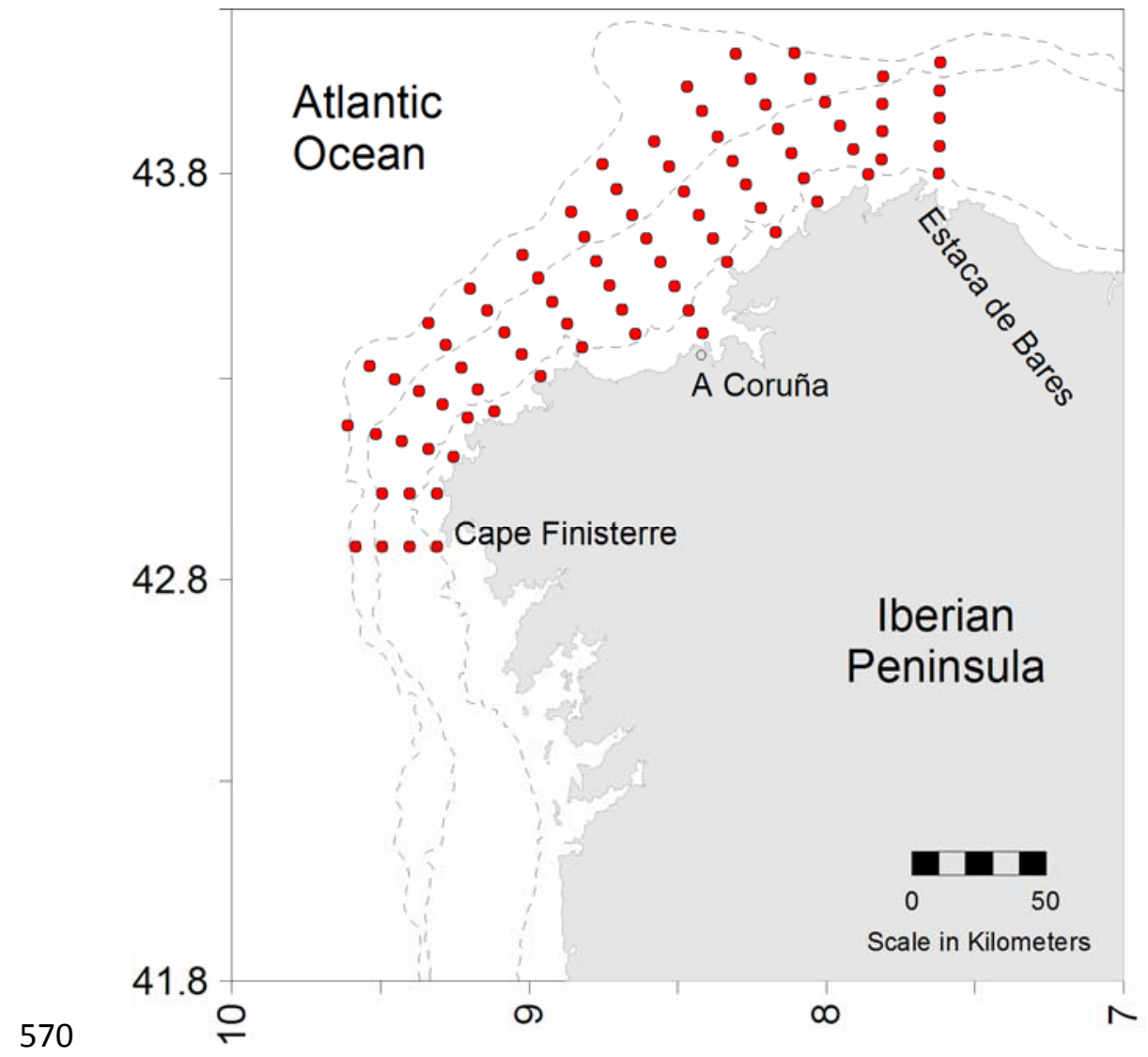

571 Fig. 1. Map of the Galician shelf (NW Iberian Peninsula). The sampling stations are represented by

572 red points, outlining a total of 15 transects. 

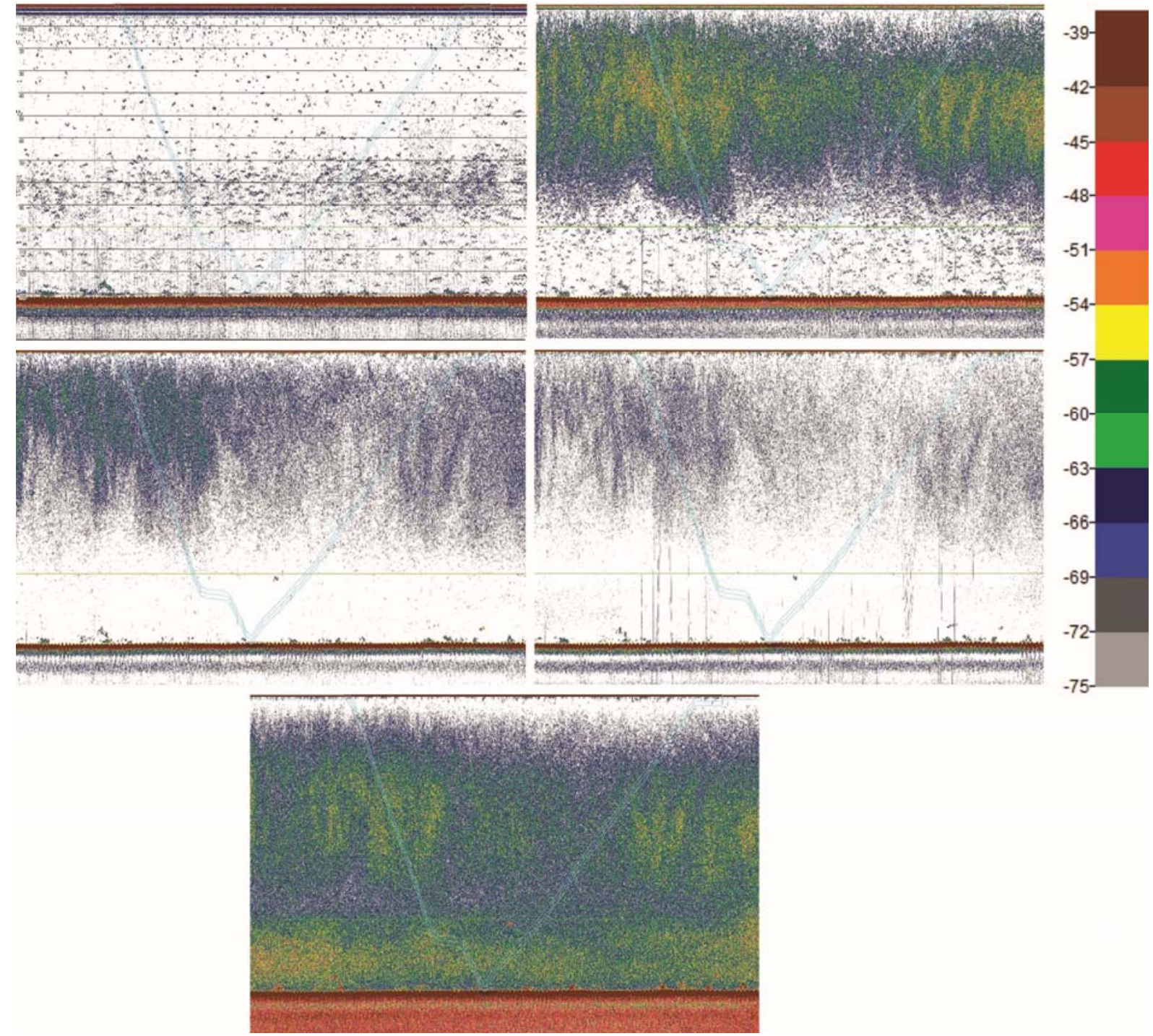

574 Fig. 2. Echogram (after noise removal) at four frequencies $(18,38,70$ and $120 \mathrm{KHz}$ ) recorded on 7

575 March 2012. The gear trajectory and the two parallel virtual lines (which delimited the analysis area)

576 are represented by turquoise lines. The scale on the right indicates the volume backscattering

577 strength $(\mathrm{dB})$ in the echogram. 


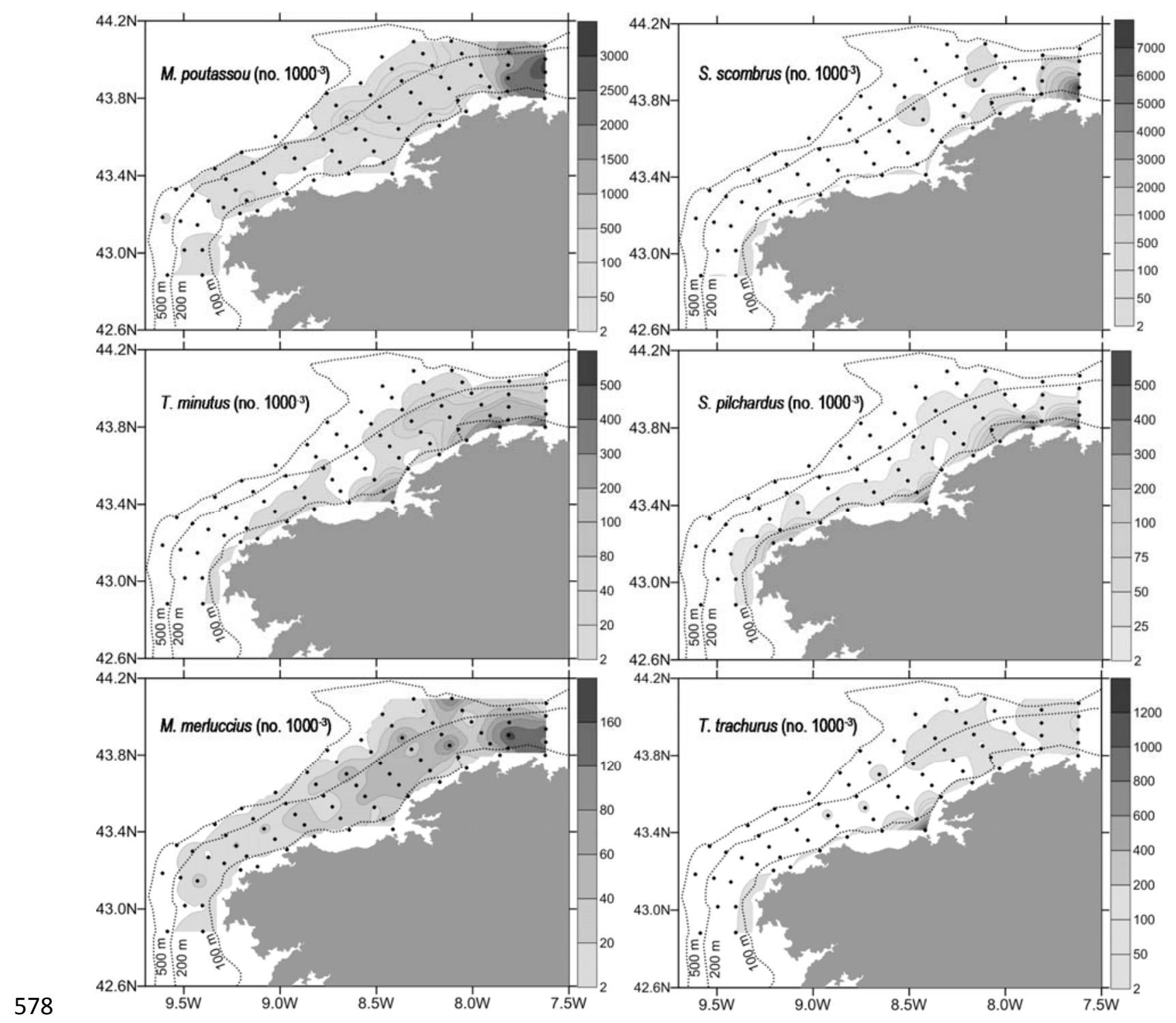

579 Fig. 3. Horizontal distribution of the larval fish densities (expressed as number of individuals 1000

$\mathrm{m}^{-3}$ ) of the six most abundant species collected by the MultiNet MiDi during the cruise. 

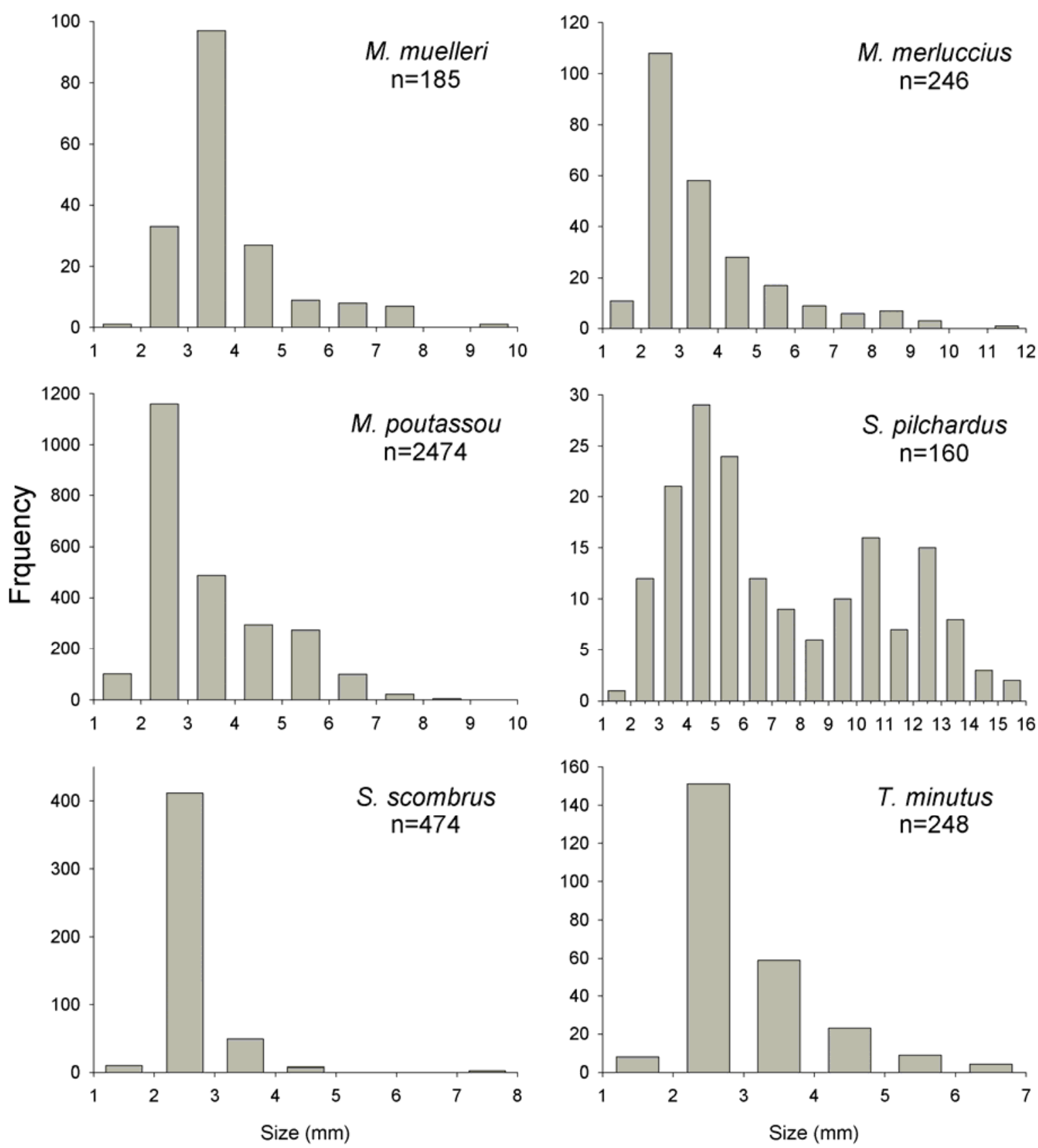

582 Fig. 4. Length frequency distributions (in $\mathrm{mm}$ ) of the six more abundant larval fish species collected by the MultiNet MiDi during the cruise. 



Fig. 5. Distribution maps of (a) larval fish density (in number of individuals $\cdot 1000 \mathrm{~m}^{-2}$ ) estimated for the whole survey (considering only larvae with functional swimbladders), (b) acoustic backscatter (NASC; $\mathrm{m}^{2} \cdot \mathrm{nmile}^{-2}$ ) at $18 \mathrm{kHz},(\mathrm{c})$ acoustic backscatter (NASC; $\mathrm{m}^{2} \cdot \mathrm{nmile}^{-2}$ ) at $38 \mathrm{kHz}$, (d) acoustic backscatter (NASC; $\mathrm{m}^{2} \cdot \mathrm{nmile}^{-2}$ ) at $70 \mathrm{kHz}$, (e) acoustic backscatter (NASC; $\mathrm{m}^{2} \cdot \mathrm{nmile}^{-2}$ ) at $120 \mathrm{kHz}$, and (f) acoustic backscatter (NASC; $\mathrm{m}^{2} \cdot \mathrm{nmile}^{-2}$ ) at $200 \mathrm{kHz}$. 
(a)

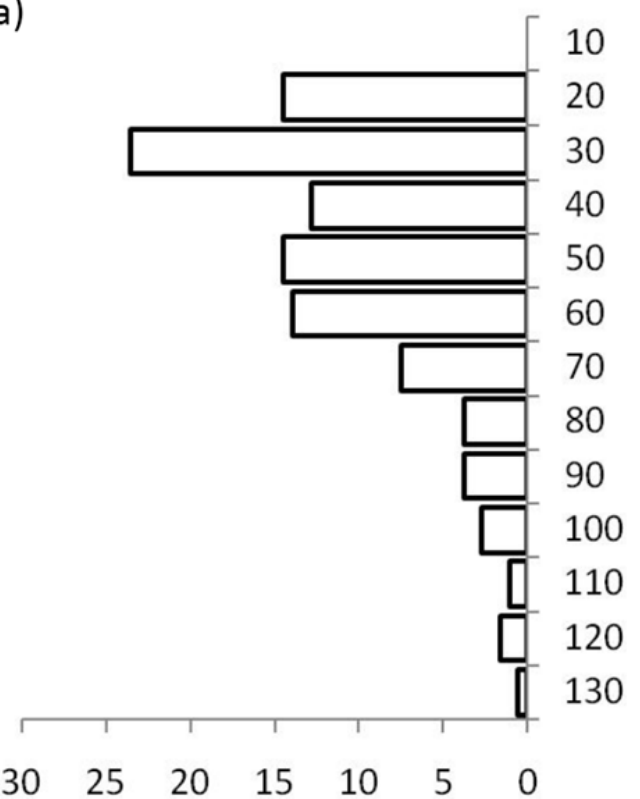

Frequency (\%) (b)

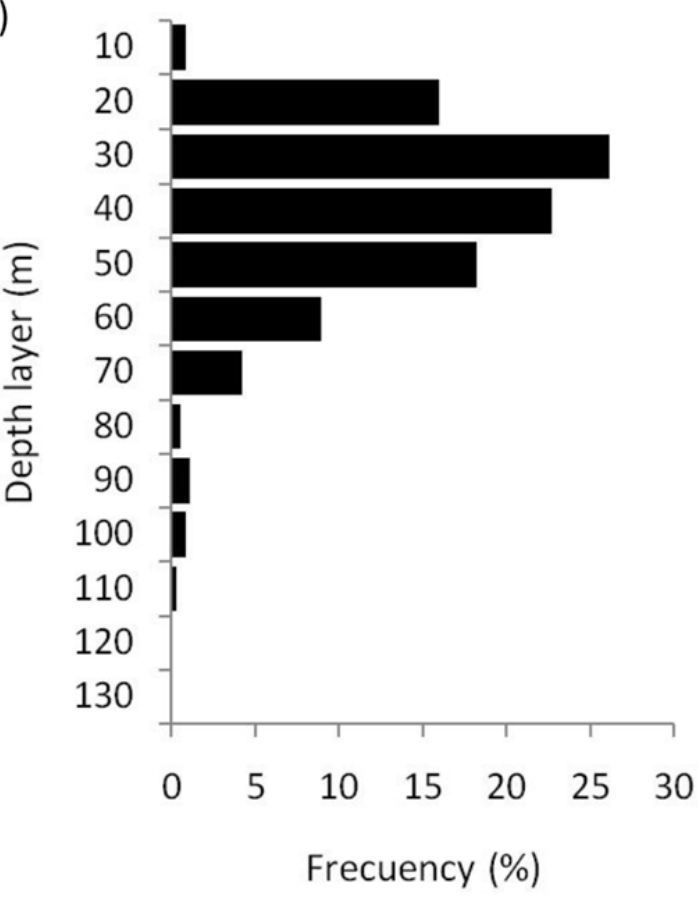

591

592 Fig. 6. Frequency of occurrence (expressed in percentage) of maximum acoustic backscattering 593 (measured as $\mathrm{S}_{\mathrm{v}}$ ) registered during the survey in each 10 meters depth for $(\mathrm{a})$ day and (b) night. 

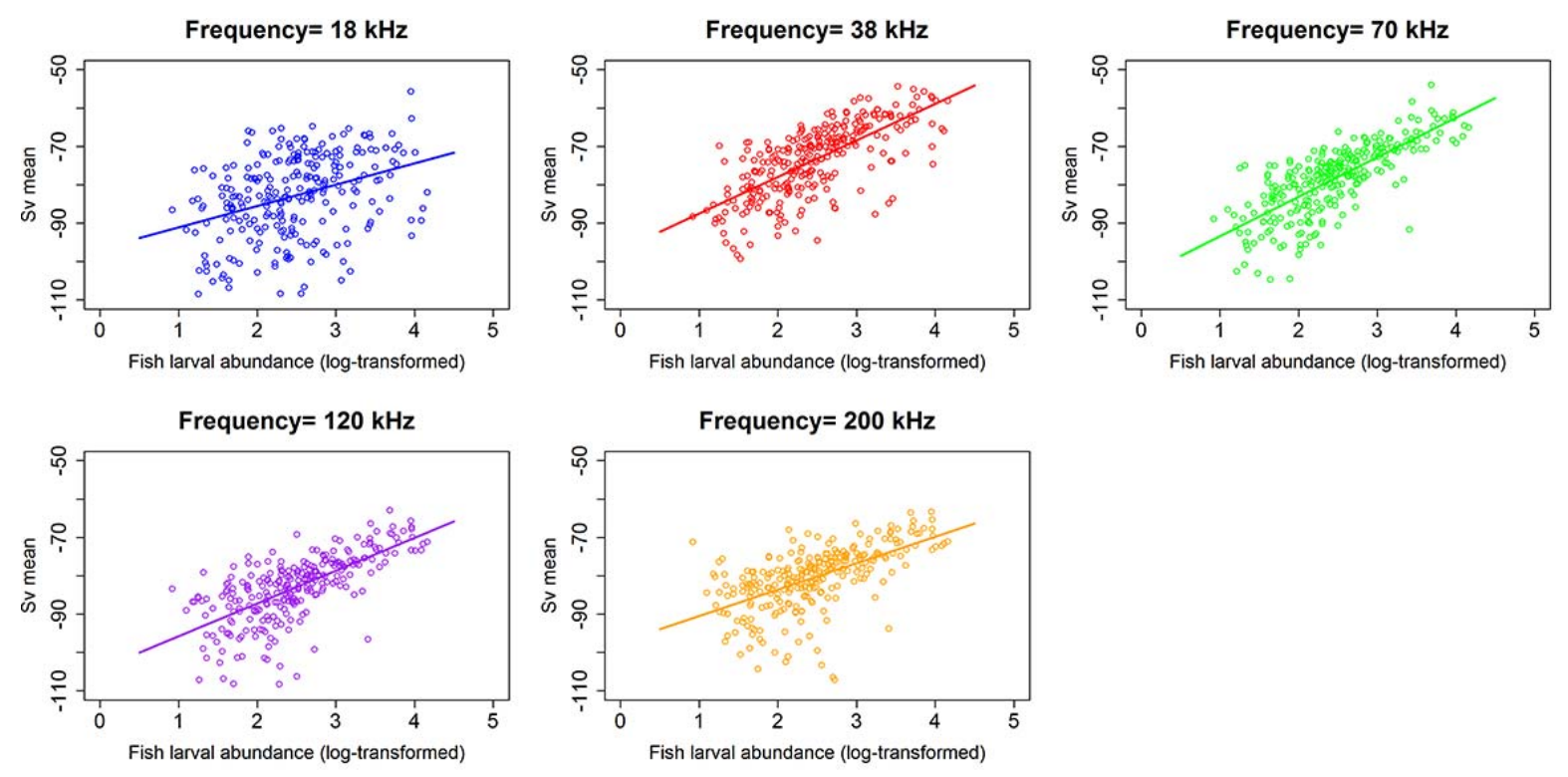

596

597 Fig. 7. Scatterplot of $S_{v}$ versus larval fish abundance (log10-transformed) estimated from the pelagic trawls (a) at $18 \mathrm{kHz}$, (b) at $38 \mathrm{kHz}$, (c) at $70 \mathrm{kHz}$, (d) at $120 \mathrm{kHz}$ and (e) at $200 \mathrm{kHz}$. 